\title{
Adrenomedullin concentrations at two time points following myocardial infarction and prediction of mid-term outcomes
}

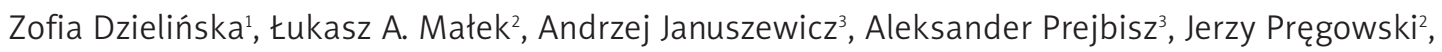
Paweł Tyczyński², Magdalena Makowiecka-Cieślaª, Jadwiga Janas ${ }^{4}$, Marcin Demkow¹, Witold Rużyłło ${ }^{5}$

\author{
1Department of Coronary Artery Disease and Structural Heart Diseases, Institute \\ of Cardiology, Warsaw, Poland \\ 2Department of Interventional Cardiology and Angiology, Institute of Cardiology, \\ Warsaw, Poland \\ 3Department of Hypertension, Institute of Cardiology, Warsaw, Poland \\ ${ }^{4}$ Department of Clinical Biochemistry, Institute of Cardiology, Warsaw, Poland \\ 5 Institute of Cardiology, Warsaw, Poland
}

Submitted: 29 October 2010

Accepted: 10 February 2011

Arch Med Sci 2011; 7, 6: 971-976

DOI: 10.5114/AOMS.2011.26608

Copyright (C) 2011 Termedia \& Banach

\begin{abstract}
Introduction: Adrenomedullin (ADM) is a vasopeptide with multiple actions in the cardiovascular system and a potentially powerful tool in comparison to some of the well-established unimodal biomarkers of risk stratification in myocardial infarction (MI). Previous studies on ADM in acute MI were based on single assessment. Therefore the aim of the study was to examine the relation between ADM plasma concentrations assessed at different time points following MI and outcomes. Material and methods: The study included 127 patients with acute MI treated with percutaneous coronary intervention and 60 healthy individuals as controls. Adrenomedullin concentration was assessed at baseline in all study subjects and $48 \mathrm{~h}$ after admission in patients with Ml. The primary endpoint consisted of all-cause death, nonfatal myocardial infarction, stroke and the need of target vessel revascularization at 6-month follow-up.

Results: Mean ADM plasma concentration on admission was higher in patients with $\mathrm{Ml}$ than in controls $(30.3 \pm 14.3 \mathrm{pmol} / \mathrm{l}$ vs. $14.6 \pm 4.7 \mathrm{pmol} / \mathrm{l}, p<0.0001)$. There was no significant difference between ADM concentration after $48 \mathrm{~h}$ $(30.6 \pm 12.3 \mathrm{pmol} / \mathrm{l})$ and on admission. The primary endpoint occurred in $9.4 \%$ of patients with MI. Multivariable analysis showed that ADM concentration at $48 \mathrm{~h}$ after admission ( $\mathrm{OR}=2.121,95 \% \mathrm{Cl} 1.180-3.810$ for every increase of $10 \mathrm{pmol} / \mathrm{l}, p=0.012$ ) was the only independent predictor of the primary endpoint. Conclusions: In patients with acute $\mathrm{MI}$ adrenomedullin plasma concentration assessed at $48 \mathrm{~h}$ after admission, but not ADM concentration at baseline, is an independent predictor of major adverse cardiovascular events at mid-term follow-up.
\end{abstract}

Key words: myocardial infarction, percutaneous coronary intervention, adrenomedullin, outcomes.

\section{Introduction}

Despite invasive and medical treatment of myocardial infarction (MI) there is a persistent risk of recurrent cardiovascular events [1]. Identification of patients at risk of those incidents remains one of the most important targets of MI management. Various cardiac biomarkers assessed on admission or in the first days of hospitalization were proposed as useful

\author{
Corresponding author: \\ Zofia Dzielińska MD, PhD \\ Department of Coronary \\ Artery Disease \\ and Structural Heart Diseases \\ Institute of Cardiology \\ 42 Alpejska \\ 04-628 Warsaw, Poland \\ Phone: +48223434342 \\ Fax: +48 226133819 \\ E-mail: zdziel@wp.pl
}


stratification measures including markers of inflammation, renal function, myonecrosis, vascular tone or platelet function [2-5].

Adrenomedullin (ADM) is a vasopeptide with multiple actions in the cardiovascular system. It was originally isolated from human pheochromocytoma, but subsequent studies discovered that endothelial cells are likely to be the major source of circulating ADM. It is a natriuretic and hypotensive peptide influencing many processes such as systemic haemodynamics, neurohormonal responses, inflammatory mediators, oxidative stress, and cellular proliferation or growth [6]. Multimodal ways of action make ADM a potentially powerful tool in comparison to some of the well-established unimodal biomarkers [2-5]. Moreover, ADM is not only a marker of cardiovascular status but exerts cytoprotective actions $[7,8]$.

Studies on plasma ADM concentrations in relation to mid- or long-term major adverse cardiovascular events in patients with acute MI are limited [9-15]. Most of them were based on single ADM assessment. There are no data about the relation between time of sampling of ADM during the first days of MI and outcomes.

Therefore, the aim of the study was to assess the relation between ADM plasma concentrations assessed at different time points after admission and outcomes in patients with acute MI.

\section{Material and methods}

\section{Study group}

The study included 127 consecutive patients with acute $\mathrm{MI}$ treated invasively (ST-elevation $75.6 \%$, mean age $63.9 \pm 12.0$, male sex $72.4 \%$ ) and 60 healthy controls (mean age $40.5 \pm 7.7$, male sex $71.7 \%$ ) from the Warsaw region defined on the basis of their personal history (no risk factors of coronary artery disease), normal resting ECG and negative exercise stress testing on a treadmill.

Diagnosis of MI was made according to contemporary guidelines $[16,17]$. Obtained information consisted of medical history, vital status, angiographic parameters and baseline laboratory parameters. Hypertension was defined as systolic blood pressure $>140 \mathrm{mmHg}$ or diastolic blood pressure $>90 \mathrm{mmHg}$ or current antihypertensive treatment. Diabetes mellitus type 2 was diagnosed according to WHO criteria or if a patient was on hypoglycaemic drugs [18]. Hyperlipidaemia was defined if the total cholesterol level was $>5.2 \mathrm{mmol} / \mathrm{l}$ or lowdensity lipoprotein (LDL) cholesterol level was > 3.4 $\mathrm{mmol} / \mathrm{l}$, or if the patient was treated with a lipidlowering drug. Previous MI was classified on the basis of medical history records. Number of diseased coronary arteries was based on the presence of $>50 \%$ stenosis in any of the major coronary arteries. All patients with $\mathrm{MI}$ underwent resting echocardiography for the assessment of left ventricular ejection fraction (LVEF) during the first $24 \mathrm{~h}$ after admission for $\mathrm{MI}$ (after the invasive treatment) using a Hewlett-Packard Sonos 2500 (HewlettPackard, Andover, MA).

The Local Ethics Committee of the Institute of Cardiology, Warsaw, Poland approved the study protocol and all patients provided written informed consent.

\section{Adrenomedullin assay}

Adrenomedullin concentration in plasma was assessed by means of immunoradiometric assay (Shionogi, Osaka, Japan) [19]. Blood was drawn from the antecubital vein on admission (in all patients with $\mathrm{MI}$ and controls) and after $48 \mathrm{~h}$ (in all $\mathrm{MI}$ patients). The detection limit was $0.5 \mathrm{pmol} / \mathrm{l}$, and the working range was $1-300 \mathrm{pmol} / \mathrm{l}$ (coefficient of variability $<15 \%)$.

\section{Primary endpoint}

Primary endpoint consisted of all-cause death, nonfatal MI, stroke and the need of target vessel revascularization at 6 months follow-up.

\section{Statistical analysis}

Baseline characteristics of study patients were summarized in terms of frequencies and percentages for categorical variables and by means and standard deviations (SD) for continuous variables with normal distribution. Categorical variables were compared by either Fisher's exact or $\chi^{2}$ test and continuous variables by Student's $t$-test or MannWhitney $U$ test for unpaired samples, when appropriate. Correlations were assessed by means of Pearson's r-test or Spearman's rho-test, when appropriate. Multivariable analysis was performed with the use of stepwise logistic regression. All significant variables from the univariable analysis entered the multivariable stage. A $p$-value (twotailed) of $<0.05$ was considered statistically significant and confidence intervals $(\mathrm{Cl})$ were $95 \%$. All data analyses were performed using SPSS version 15.0 software (SPSS Polska Sp. Z o.o., Cracow, Poland).

\section{Results}

\section{Adrenomedullin concentrations in patients with $\mathrm{MI}$ and controls}

Adrenomedullin concentration on admission was higher in patients with $\mathrm{Ml}$ than in controls $(30.3$ $\pm 14.3 \mathrm{pmol} / \mathrm{l}$ vs. $14.6 \pm 4.7 \mathrm{pmol} / \mathrm{l}, p<0.0001)$ (Figure 1). In the MI group vasopeptide concentrations did not change significantly in the first $48 \mathrm{~h}$ from admission. The absolute and relative changes 
of ADM concentration after $48 \mathrm{~h}$ in comparison to baseline in patients with $\mathrm{Ml}$ were $-0.3 \pm 13.2 \mathrm{pmol} / \mathrm{l}$ and $9.5 \pm 49.4 \%$ (in both cases $p=N S$ ).

\section{ADM concentrations and MI patients' characteristics on admission}

Baseline clinical, angiographic and laboratory characteristics of $\mathrm{MI}$ patients in relation to plasma ADM concentration on admission and after $48 \mathrm{~h}$ are presented in Table I. Adrenomedullin plasma concentration $48 \mathrm{~h}$ after admission correlated significantly with the largest number of assessed parameters including age, heart rate on admission, LVEF, as well as highsensitivity C-reactive protein (hs-CRP) and glucose level on admission. In comparison, adrenomedullin plasma concentration on admission correlated significantly with LVEF as well as creatinine, hs-CRP and glucose level on admission.

\section{Predictors of outcome in patients with $\mathrm{MI}$}

The primary endpoint occurred in 12 patients during follow-up (9.4\%). There were 6 deaths (4.7\%),

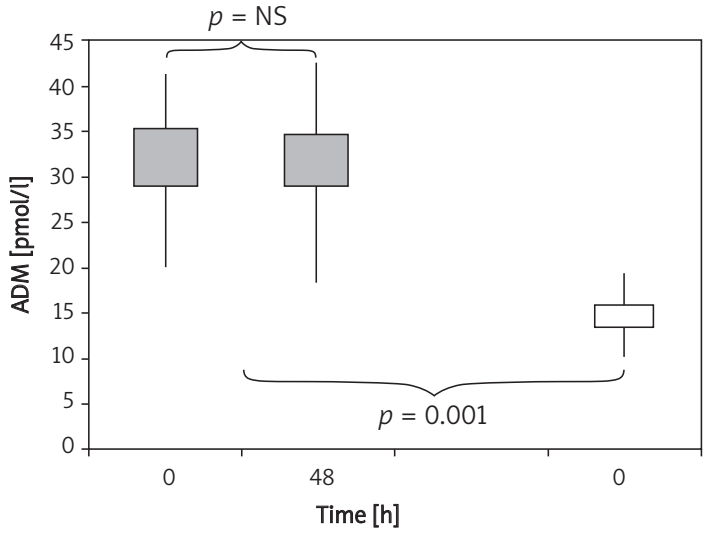

Figure 1. Plasma concentration of ADM at different time points (admission, $48 \mathrm{~h}$ ) in patients with myocardial infarction (grey bars) and controls (white bars). Bars show $95 \%$ confidence interval for mean and whiskers present standard deviation of the mean

3 nonfatal myocardial infarctions (2.35\%) and 3 target vessel revascularizations (2.35\%). Patients with the primary endpoint were older, more likely to have

Table I. Relation between ADM plasma concentration on admission/after $48 \mathrm{~h}$ and baseline characteristics

\begin{tabular}{|c|c|c|c|c|}
\hline \multirow[t]{2}{*}{ Parameter } & ADM on admission & Value of $p$ & $\mathrm{ADM}$ at $48 \mathrm{~h}$ & Value of $p$ \\
\hline & {$[\mathrm{pmol} / \mathrm{I}(\mathrm{SD})]$} & \multicolumn{3}{|c|}{$[\mathrm{pmol} / \mathrm{l}(\mathrm{SD})]$} \\
\hline Male/female sex & $30.7(14.5) / 29.2(14.0)$ & NS & $30.1(12.1) / 31.7(12.7)$ & NS \\
\hline \multicolumn{5}{|l|}{ History - no/yes } \\
\hline Hypertension & $32.3(14.4) / 29.0(14.0)$ & 0.09 & $32.2(12.5) / 29.0(12.0)$ & NS \\
\hline Diabetes & $29.7(13.3) / 34.3(19.8)$ & NS & $29.9(12.3) / 35.5(11.9)$ & NS \\
\hline Hyperlipidaemia & $32.6(15.4) / 27.8(12.8)$ & 0.06 & $31.4(13.7) / 29.7$ (10.6) & NS \\
\hline$\overline{M I}$ & $30.7(14.7) / 27.1(10.7)$ & NS & $30.3(11.7) / 34.0(18.0)$ & NS \\
\hline \multirow{3}{*}{$\begin{array}{l}\text { Current cigarette } \\
\text { Smoker - no/yes }\end{array}$} & $28.2(13.4) / 29.3(15.4)$ & NS & $28.7(12.8) / 28.4(7.6)$ & NS \\
\hline & & & & \\
\hline & Corr. coeff. & & Corr. coeff. & \\
\hline Age [years] & 0.14 & NS & 0.22 & 0.03 \\
\hline HR on admission [beats/s] & 0.06 & NS & 0.23 & 0.02 \\
\hline Systolic BP on admission [mmHg] & -0.13 & NS & -0.16 & NS \\
\hline Diastolic BP on admission [mmHg] & -0.10 & NS & -0.08 & NS \\
\hline $\begin{array}{l}\text { Number of diseased coronary } \\
\text { arteries - no. }\end{array}$ & -0.09 & NS & 0.11 & NS \\
\hline LVEF [\%] & -0.29 & 0.002 & -0.39 & $<0.001$ \\
\hline Troponin I [ng/ml] & -0.13 & NS & -0.17 & NS \\
\hline Creatinine $[\mu \mathrm{mol} / \mathrm{l}]$ & 0.30 & 0.001 & 0.18 & 0.08 \\
\hline $\mathrm{hsCRP}[\mathrm{mg} / \mathrm{dl}]$ & 0.38 & $<0.001$ & 0.38 & $<0.001$ \\
\hline Glucose [mmol/l] & 0.32 & 0.001 & 0.23 & 0.03 \\
\hline Total cholesterol [mmol/l] & -0.18 & 0.05 & -0.19 & 0.06 \\
\hline LDL cholesterol [mmol/l] & -0.07 & NS & -0.05 & NS \\
\hline
\end{tabular}

$A D M$ - adrenomedullin, BP - blood pressure, $H R$ - heart rate, hSCRP - high sensitivity C-reactive protein, LDL - low density lipoprotein, LVEF left ventricular ejection fraction, $M I-$ myocardial infarction, $S D$ - standard deviation 
Table II. Baseline characteristics of MI patients with and without the primary endpoint

\begin{tabular}{|c|c|c|c|}
\hline Parameter & $\begin{array}{l}\text { With primary endpoint } \\
\qquad(n=12)\end{array}$ & $\begin{array}{l}\text { Without primary endpoint } \\
\qquad(n=115)\end{array}$ & Value of $p$ \\
\hline Age [years] (SD) & $66.1(11.0)$ & $63.7(12.1)$ & NS \\
\hline Male sex, $n(\%)$ & $12(100)$ & $80(69.6)$ & 0.04 \\
\hline \multicolumn{4}{|l|}{ History, $n(\%)$} \\
\hline Hypertension & $5(41.7)$ & $57(49.6)$ & NS \\
\hline Diabetes & 0 & $17(14.8)$ & NS \\
\hline Hyperlipidaemia & $3(25.0)$ & $60(52.2)$ & 0.05 \\
\hline $\mathrm{Ml}$ & $5(41.7)$ & $7(6.1)$ & 0.004 \\
\hline Current cigarette smoker, $n(\%)$ & $1(8.3)$ & $12(10.4)$ & NS \\
\hline HR on admission [beats/s] (SD) & $78.1(12.5)$ & $73.8(9.0)$ & NS \\
\hline Systolic BP on admission [mmHg] (SD) & $151.1(34.2)$ & $137.4(21.1)$ & NS \\
\hline Diastolic BP on admission [mmHg] (SD) & $90.8(26.8)$ & $78.2(10.9)$ & NS \\
\hline Number of diseased coronary arteries, $n$ (SD) & $1.83(0.94)$ & $1.51(0.83)$ & NS \\
\hline LVEF [\%] (SD) & $44.3(17.6)$ & $51.2(9.4)$ & NS \\
\hline ADM on admission [pmol/I] (SD) & $33.2(15.5)$ & $30.0(14.2)$ & NS \\
\hline ADM at $48 \mathrm{~h}[\mathrm{pmol} / \mathrm{l}]$ (SD) & $44.3(19.8)$ & $29.7(11.3)$ & 0.004 \\
\hline Troponin I [ng/ml] (SD) & $9.8(26)$ & $5.3(11.8)$ & NS \\
\hline Creatinine $[\mu \mathrm{mol} / \mathrm{l}]$ (SD) & $91.2(36.9)$ & $77.7(25.7)$ & NS \\
\hline hsCRP [mg/dl] (SD) & $1.3(2.4)$ & $0.7(1.8)$ & NS \\
\hline Glucose [mmol/l] (SD) & $8.6(3.2)$ & $7.2(2.8)$ & NS \\
\hline Total cholesterol [mmol/l] (SD) & $5.2(0.6)$ & $5.1(1.2)$ & NS \\
\hline LDL cholesterol [mmol/l] (SD) & $3.6(0.9)$ & $3.7(2.6)$ & NS \\
\hline
\end{tabular}

$A D M$ - adrenomedullin, $B P$ - blood pressure, $H R$ - heart rate, hSCRP - high sensitivity C-reactive protein, $L D L$ - low density lipoprotein, $L V E F$ - left ventricular ejection fraction, MI- myocardial infarction, SD - standard deviation

a history of MI and less likely to have hyperlipidaemia than those without the primary endpoint (Table II). They had a higher concentration of ADM at $48 \mathrm{~h}$, but not on admission in comparison to

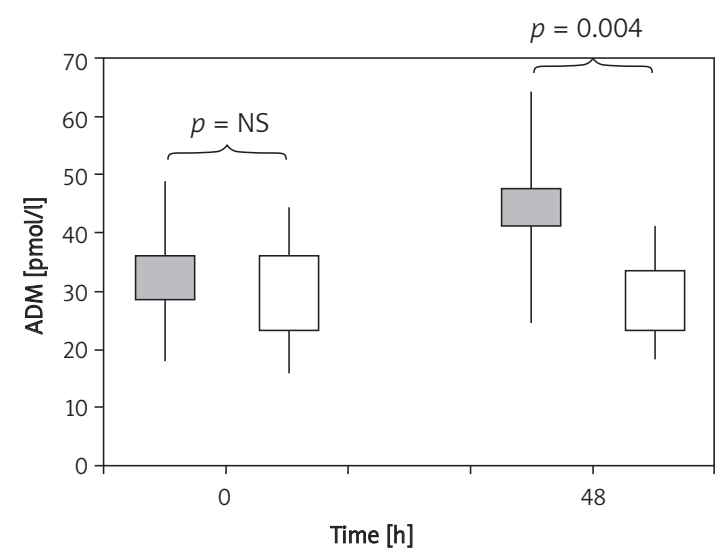

Figure 2. Plasma concentration of ADM at different time points (admission, $48 \mathrm{~h}$ ) in patients with (grey bars) and without (white bars) the primary endpoint. Bars show 95\% confidence interval for mean and whiskers present standard deviation of the mean patients without the events (Figure 2). There was a significant increase of ADM concentration over time in patients with the events $(p=0.01)$, but not in those without the events.

The multivariable analysis model including age, history of MI, hyperlipidaemia and ADM concentration at $48 \mathrm{~h}$ showed that ADM concentration at $48 \mathrm{~h}$ after admission was the only independent predictor of the primary endpoint $(\mathrm{OR}=2.121,95 \% \mathrm{Cl}$ $1.180-3.810$ for every increase of $10 \mathrm{pmol} / \mathrm{l}, p=0.012$ ).

\section{Discussion}

We demonstrate that plasma ADM measured at $48 \mathrm{~h}$ after admission can be an independent predictor of mid-term major adverse cardiovascular events. Although we cannot directly explain the pathomechanism of that relation, we show that ADM plasma concentration $48 \mathrm{~h}$ after admission correlates with the largest number of baseline clinical and laboratory parameters. Those parameters included markers of inflammation (hs-CRP on admission), cardiac dysfunction (LVEF) and haemodynamic status (heart rate on admission), 
which suggests the vasopeptide's multimodal way of action and makes it a good candidate for a marker of future adverse events.

Previous studies on the relation between ADM plasma concentration and events during followup were based on a single sampling performed during the hospitalization, but not on admission for MI. In the study by Nagaya et al., plasma ADM on day 2 was the only non-invasive variable to independently predict mortality at 25 months followup after MI [9]. Similar findings come from the small study of Katayama et al., where plasma ADM concentration obtained at $24 \mathrm{~h}$ after the onset of $\mathrm{MI}$ was the strongest predictor of 1-year mortality in multivariate analysis [10]. In contrast, in the Richards et al. study, adrenomedullin assessed at day 2 to 4 after $\mathrm{MI}$ discriminated patients in relation to death in univariate analysis, but in contrast to $\mathrm{N}$-terminal pro-brain natriuretic peptide it did not provide independent predictive information on death and left ventricular failure at 24 months follow-up [11]. According to the authors, the results might have been influenced by the fact that ADM levels in heart failure presumably reflect a more systemic or peripheral response to cardiac impairment instead of the ventricular response itself (such as for natriuretic peptides). However, in two recent studies it was demonstrated that a mid regional pro-ADM (MR-proADM) assessed after 3 to 5 days in patients with ST-elevation myocardial infarction or within $36 \mathrm{~h}$ in patients with non-ST-elevation myocardial infarction is a powerful predictor of adverse outcome and adds further prognostic information over NT-proBNP and commonly used risk scores $[14,15]$. It is worth noting that in the latter study MR-proADM concentrations assessed within $36 \mathrm{~h}$ from the onset of symptoms were a better predictor of outcome than the marker levels at discharge [15]. Earlier sampling of ADM (up to $48 \mathrm{~h}$ after the onset of symptoms) may be more justified than late assessment (after day 3) as most of the initial studies reported peak ADM concentrations in plasma to occur in the acute phase of $\mathrm{MI}$ $[20,21]$.

Our results confirm the previous findings that ADM concentration assessed in the first days after admission is an independent predictor of clinical outcome. We have also discovered that biomarker levels on admission were of no predictive value for outcomes in the studied group. At the same time thre was no significant rise in ADM concentration in plasma at $48 \mathrm{~h}$ after admission in patients with $\mathrm{MI}$ in comparison to baseline. However, despite a similar mean level of ADM concentration over time in the whole studied group, there was an increase in mean plasma ADM concentration in time in $\mathrm{MI}$ patients who suffered from the major adverse cardiovascular event during follow-up in comparison to patients without the event, whose mean ADM concentration remained unchanged during the first $48 \mathrm{~h}$ after admission.

The first limitation of our study is the fact that despite being the largest study to date we were unable to analyse the relation between ADM concentration and individual components of the primary endpoint. Secondly, although differences in patients' age between the study group and controls may be potentially considered as a confounding factor, previous studies showed no significant variations of ADM plasma concentration with respect to sex and age [22].

We believe that ADM concentration at $48 \mathrm{~h}$ after admission or its increase during the first days of acute MI may be a good predictor of future outcome beyond markers included in most of the currently used risk scores such as ejection fraction or other biomarker levels.

In conclusion, our study indicates that in patients with acute $\mathrm{MI}$, adrenomedullin plasma concentration assessed at $48 \mathrm{~h}$ from admission, but not at baseline, is an independent predictor of major adverse cardiovascular events at mid-term follow-up.

\section{Acknowledgments}

The study was supported by grant 2PO5B06727 from the Polish Committee for Scientific Investigation.

\section{References}

1. Van de Werf F, Bax J, Betriu A, et al. Management of acute myocardial infarction in patients presenting with persistent ST-segment elevation: the Task Force on the Management of ST-Segment Elevation Acute Myocardial Infarction of the European Society of Cardiology. Eur Heart J 2008; 29: 2909-45.

2. Ferreirós ER, Boissonnet CP, Pizarro R, et al. Independent prognostic value of elevated C-reactive protein in unstable angina. Circulation 1999; 100: 1958-63.

3. Uyarel H, Cam N, Ergelen M, et al. Contrast-induced nephropathy in patients undergoing primary angioplasty for acute myocardial infarction: incidence, a simple risk score, and prognosis. Arch Med Sci 2009; 5: 550-8.

4. Grabowski M, Filipiak KJ, Malek LA, et al. Admission Btype natriuretic peptide assessment improves early risk stratification by Killip classes and TIMI risk score in patients with acute ST elevation myocardial infarction treated with primary angioplasty. Int J Cardiol 2007; 115: 386-90.

5. Sabatine MS, Morrow DA, de Lemos JA, et al. Multimarker approach to risk stratification in non-ST elevation acute coronary syndromes: simultaneous assessment of troponin I, C-reactive protein, and B-type natriuretic peptide. Circulation 2002; 105: 1760-3.

6. Hamid SA, Baxter GF. Adrenomedullin: regulator of systemic and cardiac homeostasis in acute myocardial infarction. Pharmacol Ther 2005; 105: 95-112.

7. Nakamura R, Kato J, Kitamura K, et al. Adrenomedullin administration immediately after myocardial infarction 
ameliorates progression of heart failure in rats. Circulation 2004; 110: 426-31.

8. Nishida H, Sato T, Miyazaki M, Nakaya H. Infarct size limitation by adrenomedullin: protein kinase $A$ but not PI3-kinase is linked to mitochondrial KCa channels. Cardiovasc Res 2008; 77: 398-405.

9. Nagaya N, Nishikimi T, Uematsu M, et al. Plasma adrenomedullin as an indicator of prognosis after acute myocardial infarction. Heart 1999; 81: 483-7.

10. Katayama T, Nakashima H, Takagi C, Honda Y, Suzuki S Yano K. Predictors of mortality in patients with acute myocardial infarction and cardiogenic shock. Circ J 2005; 69: 83-8.

11. Richards AM, Nicholls MG, Yandle TG, et al. Plasma N-terminal pro-brain natriuretic peptide and adrenomedullin: new neurohormonal predictors of left ventricular function and prognosis after myocardial infarction. Circulation 1998; 97: 1921-9.

12. Kobayashi K, Kitamura K, Hirayama N, et al. Increased plasma adrenomedullin in acute myocardial infarction. Am Heart J 1996; 131: 676-80.

13. Miyao Y, Nishikimi T, Goto Y, et al. Increased plasma adrenomedullin levels in patients with acute myocardial infarction in proportion to the clinical severity. Heart 1998; 79: 39-44.

14. Khan SQ, O'Brien RJ, Struck J, et al. Prognostic value of midregional pro-adrenomedullin in patients with acute myocardial infarction: the LAMP (Leicester Acute Myocardial Infarction Peptide) study. J Am Coll Cardiol 2007; 49: 1525-32.

15. Dhillon OS, Khan SQ, Narayan HK, et al. Prognostic value of mid-regional pro-adrenomedullin levels taken on admission and discharge in non-ST-elevation myocardial infarction. J Am Coll Cardiol 2010; 56: 125-33.

16. Task Force on the Management of Acute Myocardial Infarction of the European Society of Cardiology. Management of acute myocardial infarction in patients presenting with ST-segment elevation. The Task Force on the Management of Acute Myocardial Infarction of the European Society of Cardiology. Eur Heart J 2003; 24: 28-66.

17. Task Force for Diagnosis and Treatment of Non-STSegment Elevation Acute Coronary Syndromes of European Society of Cardiology. Guidelines for the diagnosis and treatment of non-ST-segment elevation acute coronary syndromes. Eur Heart J 2007; 28: 1598-660.

18. Task Force on Diabetes and Cardiovascular Diseases of the European Society of Cardiology (ESC); European Association for the Study of Diabetes (EASD). Guidelines on diabetes, pre-diabetes, and cardiovascular diseases: executive summary. The Task Force on Diabetes and Cardiovascular Diseases of the European Society of Cardiology (ESC) and of the European Association for the Study of Diabetes (EASD). Eur Heart J 2007; 28: 88-136.

19. Ohta H, Tsuji T, Asai S, et al. A simple immunoradiometric assay for measuring the entire molecules of adrenomedullin in human plasma. Clin Chim Acta 1999; 287: 131-43.

20. Kobayashi K, Kitamura K, Hirayama N, et al. Increased plasma adrenomedullin in acute myocardial infarction. Am Heart J 1996; 131: 676-80.

21. Miyao Y, Nishikimi T, Goto Y, et al. Increased plasma adrenomedullin levels in patients with acute myocardial infarction in proportion to the clinical severity. Heart 1998; 79: 39-44.

22. Lewis LK, Smith MW, Yandle TG, Richards AM Nicholls MG. Adrenomedullin (1-52) measured in human plasma by radioimmunoasay: plasma concentration, adsorption, and storage. Clin Chem 1998; 44: 571-7. 